\title{
Atypical course of Henoch-Schonlein purpura in an adult patient
}

\author{
Agnieszka Bielewicz-Zielińska' ${ }^{1}$ Bożena Górnikiewicz-Brzezicka², Jan Brzezicki², Marcin Rymko³, \\ Stawomir Jeka ${ }^{4}$ \\ ${ }^{1}$ Department of Rheumatology, Voivodeship Hospital, Elbląg, Poland \\ ${ }^{2}$ Clinical-Research Center, Elblag, Poland \\ ${ }^{3}$ NZOZ Nasz Lekarz, Clinical Trials Office, Toruń, Poland \\ ${ }^{4}$ University Hospital Nr 2 Dr. Jan Biziel, Bydgoszcz, Collegium Medicum in Bydgoszcz, \\ Nicolaus Copernicus University in Torun, Poland
}

\begin{abstract}
Henoch-Schonlein purpura is vasculitis of small blood vessels characterized by deposits of IgA immune complexes and also non-thrombocytopenic purpura, abdominal pain, arthritis and renal involvement. It affects people of all ages, but most cases occur in children between 2 and 11 years old, more frequently in boys. The disease is much less common in adults, who often have a more severe course of the disease. The paper presents the case of a 38-year-old female patient with insidious course of the disease, initially dominant skin symptoms and joint pain without signs of inflammation. Symptoms of the disease were initially uncharacteristic and mild, and did not suggest severe and rapid course of the disease. The patient required hospitalization in several departments before final diagnosis of Henoch-Schonlein purpura. The patient was treated with corticosteroids and immunosuppression. Despite the rapid course of the disease, treatment was effective. The patient was discharged in good condition.
\end{abstract}

Key words: arthritis, purpura, immunosuppression

\section{Introduction}

Henoch-Schonlein purpura is small blood vessel vasculitis associated with deposits of IgA [1]. Peak incidence is at $4-5$ years of age [1]. The disease in adults is associated with a much more severe course [2]. In the pathogenesis of the disease incorrect autoimmune reaction associated with exposure to exogenous antigens plays a major role [3]. The disease may begin with upper respiratory tract infection [4], often for several days preceding symptoms of the disease. Microorganisms occurring in relation with such an infection and Henoch-Schonlein purpura are the B-hemolytic streptococci, Mycobacterium tuberculosis, Escherichia coli, Mycoplasma pneumoniae, cytomegalovirus (CMV), Epstein-Barr virus (EBV), Varicella zoster virus (VZV), adenoviruses and parvoviruses [2]. Other factors initiating the disease are medi- cation, insect bites, food and immunization [4]. In adult patients the clinical course and manifestation are not the same as in children [5]. Palpable purpura occurs in all pediatric patients.

Kidney changes occur in $10-50 \%$ of patients and are usually characterized by mild glomerulonephritis [4]. In adults, symptoms usually concern the skin and joints, and less frequently the first symptoms of disease are ailments of the intestines. Some studies have shown that kidney changes are more extensive and more severe in adults. Changes in heart muscle can occur in adults, but are rare in children [4]. Henoch-Schonlein purpura is differentiated from drug reactions, inflammation, bacterial endocarditis, leukocytoclastic vasculitis in the course of other diseases, and polyarteritis nodosa [6]. Some authors emphasize the relationship with cancer. In adults there have been described a few cases of the disease, 
accompanied by blood cancers [2], also with lupus nephritis and other forms of bleeding disorders, and rheumatic fever [7]. Diagnosis is based on clinical symptoms and histopathology of a skin sample. Kidney biopsy may be indicated only in case of proteinuria or hematuria, active urinary sediment, and renal dysfunction [8]. The are no specific laboratory tests, and diagnosis is generally based on the clinical presentation [6]. There is no specific treatment for Henoch-Schonlein purpura [9].

\section{Case report}

The female, aged 38, noticed lesions of skin of lower legs, buttocks and upper limbs and lower leg swelling. Two days earlier there was left knee pain without swelling and redness. The patient has not suffered from chronic illnesses, and she reported duodenitis and Helicobacter pylori infection. She used only contraceptives. Three days late, she was admitted to the Dermatology Department for diagnosis of skin changes. In physical examination at admission purpura was found located within the lower legs, buttocks and upper limbs, as well as swelling of the lower legs and hands and left knee pain. Then the patients received dexamethasone $-4 \mathrm{mg}$ 2 times a day and phenazolinum. During hospitalization, the patient had severe abdominal pain. In abdominal ultrasound examination there were no deviations besides a small amount of fluid in the small pelvis and fluid in Morison's pouch. The gynecological examination without deviation beyond a trace of fluid in the pelvis. After surgical consultation the patient was transferred to the Surgery Department, where exploratory laparoscopy was performed. Straw-filmy effusion was found in the minor pelvis, the appendix was unchanged, and genital organs were without any visible change. The last loop of small intestine infiltrated, inflamed thickened walls with raspberry spots, visible effusion under her serous membrane, intestine thickened and stiff. The patient was diagnosed with peritonitis, inflammation of the terminal ileum, and suspected Crohn's disease. Histopathological examination of fluid from the peritoneal cavity did not reveal tumor cells. Antibiotics were introduced - cefuroxime (intravenously 1500 mg three times a day), metronidazolum (intravenously $500 \mathrm{mg}$ three times a day) and on the $10^{\text {th }}$ day of hospitalization Mesalazinum (1500 mg two times a day) was added. After stabilizing the patient treatment was continued in the Department of Dermatology. Then, the patient reported the occurrence of loose stools, occasional vomiting and low-grade fever, joint pain and swelling of hands and ankles, as well as new purpuric changes in the mucous membranes of the mouth. On the $13^{\text {th }}$ day of hospitalization chest pain occurred, so the patient was transferred to the Cardiology Division with suspected pulmonary embolism (D-dimers 4713, hsTroponina 0.0003). Angio$\mathrm{CT}$ (computed tomography) revealed the presence of thrombi at the site of the intermediate artery bifurcation of the right lung and its branches. The patient was treated with anticoagulants - initially heparin $5000 \mathrm{IU}$ bolus, followed by Enoxaparinum natricum 2 times a day $60 \mathrm{mg}$, yielding improvement of the patient.

After rheumatological consultation the patient was transferred to the rheumatology division for further diagnosis. In the ward from the date of admission methyloprednisolon orally was introduced, and at the same time methylprednisolone in a $500 \mathrm{mg}$ dose in intravenous pulses for 3 days and one $250 \mathrm{mg}$ pulse, then oral treatment at a dose of $48 \mathrm{mg} /$ day was maintained, and mesalazinum was discontinued. Anticoagulation and antibiotic therapy were maintained.

During hospitalization in the laboratory results there were observed increasing erythrocyturia 15-30 HPF, proteinuria to $697.8 \mathrm{mg} / \mathrm{dl}$, protein loss $4.39 \mathrm{~g} / 24 \mathrm{~h}$, creatinine $0.55 \mathrm{mg} / \mathrm{dl}$, hypokalemia $3.2 \mathrm{mmol} / \mathrm{l}$, increasing leukocytosis to $34.46 \mathrm{~K} / \mathrm{Ul}$ likely post-steroid and/or in the course of the disease, erythrocytes $4.82 \mathrm{M} / \mathrm{l}$, platelets $389,9 \mathrm{~K} / \mathrm{l}$, hemoglobin $13.3 \mathrm{~g} / \mathrm{dl}$, hematocrit of $40 \%$, D-dimer 3453, ESR - 42, AST 65 U/I ALAT 45 U/l, CRP $63 \mathrm{mg} / \mathrm{l}, \mathrm{ANA}$ at HEP-2 (anti-nuclear antibody screening using Hep-2 cells) titer of 1 : 320, anti-cardiolipin IgA, IgM, IgG-negative, B2-glycoprotein antibodies IgM, IgG - negative, ANCA - negative, ASCA-IgA in normal range, IgG ASCA $12.03(N<10)$, anti-CCP $1.22 \mathrm{U} / \mathrm{ml}$, TSH 2.23, fT3 - 3.77, fT4 - 22.9, total protein $4.94 \mathrm{~g} / \mathrm{dl}$, procalcitonin $0.18,49.11 \%$ albumin, $\alpha_{1}$-globulins $6.14 \%, \alpha_{2}$-globulins $12.78 \%, \beta_{1}$-globulins $10.01 \%$, $\gamma$-globulins $14.55 \%$, negative urine and blood cultures, throat-swab revealed normal flora.

Results of chest X-ray were without deviations. The result of echocardiography (cardiac echocardiography) was within normal limits. Based on the clinical picture and laboratory results Henoch-Schonlein purpura was suspected. To complete the diagnosis a biopsy of skin and muscle was performed. In the obtained result of the histopathological examination, there were no vascular inflammatory changes. Waiting for the laboratory results, in tandem with steroid therapy, azathioprine therapy was included at a dose of $100 \mathrm{mg} /$ day. In addition, the patient received perindopril $5 \mathrm{mg}$ /day, furosemidum initially intravenously $80 \mathrm{mg} 3$ times a day, then reduced to $40 \mathrm{mg} /$ day orally and spironolactone $25 \mathrm{mg}$ /day, subcutaneous anticoagulant treatment was stopped, ASA (acetylsalicylic acid) $75 \mathrm{mg} /$ day was started and analgesic paracetamol was administered if necessary. Gradual improvement of the patient's status was achieved. There was a reduction in proteinuria to $33.4 \mathrm{mg} / \mathrm{dl}$, pro- 
tein loss 1.53 g/24 h, CRP 6 mg /l, OB 12, AST 35 U/l, ALAT $42 \mathrm{U} /$, leukocytes $27.6 \mathrm{~K} / \mu \mathrm{l}$.

Gradually improvement was observed in the patient, both clinically and in laboratory tests. The patient was discharged from the hospital in good general condition.

\section{Discussion}

The new nomenclature of the International Chapel Hill Consensus Conference 2012 classifies HenochSchonlein purpura as an immune complex small vessel vasculitis (IgA vasculitis) [8, 10-12].

Incidence of Henoch-Schonlein purpura in children is 10.5-22/100,000 a year, and among adults is much lower (about 1.2/100,000 per year) [3]. The prognosis is good for children, worse in adults [3].

Adults are much more likely to present joint pain and rapidly progressive glomerulonephritis. In our patient symptoms were preceded by a respiratory infection, initially not feverish. The first symptom was a sore knee without signs of inflammation, which did not arouse anxiety in the patient. Only the skin lesions prompted the patient to report to a doctor. One of the diagnostic criteria of Henoch-Schonlein purpura is a hemorrhagic palpable purpura located on the limbs and buttocks [10], as in this case and joints. Purpura is a constant symptom. Relapses of rashes are possible, and blisters and hemorrhagic necrosis may occur [6]. It occurs in $90 \%$ of cases [10]. In adults it is dominated by a symmetric erythematous rash appearing around the hydrostatic pressure dependent areas, i.e. the legs and buttocks [2]. An important element is the lack of disappearance of purpuric changes during the tribulation, resulting from the severity of inflammation [2]. The changes observed in vascular flow, which is included in the differential diagnosis, disappear during the tribulation [2]. Purpura was also differentiated from drug reactions; however, before the onset of symptoms the patient used drugs previous ly without complications. In order to exclude bacterial endocarditis echocardiography was performed, which showed no abnormalities.

IgA vasculitis should also be distinguished from leukocytoclastic vasculitis occurring in the course of other diseases such as e.g. nodular arteritis: there are no neurological symptoms, hypertension, which occurred in the further course of the disease, the absence of HBsAg, and HCV antibody (HCV infection and HBV especially often coexist with above-mentioned vasculitis) [6].

In a study conducted in the years 1983-2000 in eleven French medical centers in 250 adult patients there were deaths observed in the course of cancer. Among these, $14 \%$ were caused by lung cancer, and $8 \%$ by a tumor of the gastrointestinal tract [5]. However, no evi- dence was found on the possibility of paraneoplastic origin of Schonlein-Henoch purpura [5]. In our patient there were no clinical data or evidence suggesting cancer. Also conducted tests excluded such a suspicion.

A particularly important diagnostic tool is a skin biopsy. Leukocytoclastic inflammation is confirmed with the presence of deposits of IgA, complement component C3 and fibrinogen in vessels wall [2]. In our patient a biopsy of skin and muscle was performed and no deposits of IgA were found. Perhaps it was caused by late rheumatological diagnosis and already included treatment with corticosteroids.

Symptoms of the gastrointestinal tract are common, particularly in children $[12,13]$. Abdominal pain is the second most common symptom characteristic for the disease. It appears in $65-75 \%$ of patients. Usually it is located in the periumbilical area and is of colic character. Gastrointestinal bleeding is a consequence of hemorrhagic gastritis, duodenitis and enteritis [2]. In the case described, the patient had severe abdominal pain, initially without diarrhea, with no bleeding from the gastrointestinal tract. In abdominal ultrasonography and gynecological examination, apart from a small amount of fluid in the minor pelvis, no deviations from the norm were found.

However, the severity of symptoms and the patient's condition required decisions to be made about surgical intervention and the implementation of laparoscopy. During the procedure there were revealed inflammatory changes mainly in the small intestine. In the course of the disease the small intestine is most often affected [14]. The suspicion of Crohn's disease arose. Therefore a blood sample was examined for ASCA antibody (antiSaccharomyces cerevisiae), which occurs in $60 \%$ of patients with Crohn's disease. The presence of ASCA, both IgA and IgG, is specific for this disease [8]. In our patient ASCA IgA was negative, and IgG was slightly above normal. During the procedure, fluid was also collected from the peritoneal cavity, in which there was no presence of tumor cells.

Further symptoms that occurred in our patient were pain and swelling of joints of the hands and ankles and previously left knee pain without evidence of synovitis. Arthralgia affects 2/3 of patients. Typically, painful and/ or swollen large joints are affected, mostly knee and ankle [13]. Arthritis resolves without complications [12]. This is yet another symptom that belongs to the diagnostic criteria of Henoch-Schonlein purpura. In this case, the patient reported pain in the chest, heart attack was excluded, but the angio-CT revealed a blood clot in an intermediate artery bifurcation of the right lung. Once applied anticoagulant therapy achieved improvement of the patient. The cardiac symptoms are not included in 
the diagnostic criteria of the disease because cardiac in volvement occurs very rarely [2]. During hospitalization in the Department of Rheumatology a growing hematuria was observed, and proteinuria meeting the criteria of nephrotic syndrome.

Renal involvement relates to $30 \%$ of cases of HenochSchonlein purpura in children and $60 \%$ in adults [14]. Renal involvement usually manifests itself a few days or weeks after the onset of systemic symptoms [15]. The most common manifestation is a segmental, focal glomerulonephritis, always associated with deposits of IgA in the mesangium. If symptoms are severe, renal biopsy should be performed, especially if daily protein loss is $>1 \mathrm{~g}$ or renal failure is progressing. The prevalence of chronic kidney disease in children is $18 \%$, in adults $28 \%$ [16]. The main prognostic role is played by histopathology. The percentage of crescents, interstitial fibrosis, and subepithelial dense deposits correlates with a risk of chronic kidney disease.

In adults, the percentage of development of crescents is associated with an unfavorable course in less than 50\% [16]. Adverse prognostic factors are assumed to be a high level of creatinine, proteinuria greater than 1 g/day, hypertension, proteinuria increase, vascular proliferation in biopsies, interstitial fibrosis, and renal tubular atrophy [17]. In the described patient, there was no increase in levels of creatinine, but poor prognostic factors were significant proteinuria and hypertension. In the patient renal biopsy was not performed due to the patient's severe condition and the need for quick implementation of treatment.

Henoch-Schonlein purpura was diagnosed despite the lack of specific laboratory tests; it was based on the clinical picture and the diagnostic criteria of this disease. In mild purpura the treatment is symptomatic [3]. During the initial phase this is removal of foci of inflammation with antibiotics, while in the case of involvement of the gastrointestinal tract and/or joints it is glucocorticoids, and in nephritis, depending on the histopathology, it is steroids and cytotoxic drugs [6]. In refractory cases of renal changes intravenously cyclofosfamid pulsed for 6 months can be applied [17]. When no improvement occurs, plasmapheresis is used, dialysis or a kidney transplant [6]. In patients with contraindications to the use of immunosuppressive therapy (infections, old age) intravenous infusions of immunoglobulin can be considered.

In our patient, due to the rapid course of the disease, the serious patient condition, and multi-organ symptoms, it was decided immediately to use intravenous and oral corticosteroids. While waiting for the results of laboratory tests simultaneously with corticosteroids, treatment with azathioprine was started. In addition, the patient received pressure-lowering drugs, anticoag- ulants, and antibiotics. Gradual improvement was observed in the patient, both in clinical and in laboratory parameters [18].

\section{Summary}

In summary, Henoch-Schonlein purpura, although more common in children, can also occur in adults. However, its progress in adults differs significantly from the disease occurring in children. It is an interdisciplinary disease, with rapid course, as shown in the described patient. It can cause diagnostic difficulties, and requires quick therapeutic decisions, even without a fully completed diagnosis, and the outcome is not always as successful as in the present case.

The authors declare no conflict of interest.

\section{References}

1. Małecki R, Staworska K, Frankowski M, et al. Plamica Schönleina-Henocha o ciężkim przebiegu z zajęciem przewodu pokarmowego. Reumatologia 2012; 50: 61-65.

2. Wardyn K, Życińska K, Życiński K. Plamica Schönleina-Henocha. Pierwotne układowe zapalenie naczyń. Wydawnictwo Medyczne Urban \& Partner, Wrocław 2004; 284-288.

3. Bujakowska O, Saracyn M, Kur-Zalewska J, et al. Dramatyczny przypadek plamicy Schönleina-Henocha u osoby dorosłej. Reumatologia 2013; 51: 229-232.

4. Fauci A, Pazdur J. Plamica Schönleina-Henocha. Harrison - Reumatologia. Wyd. II. Wydawnictwo Czelej, Lublin 2012; 188189.

5. Pillebout E, Thervet E, Hill G. Henoch-Schonlein purpura in adults: outcome and prognostic factors. J Am Soc Nephrol 2002; 13; 1271-1278.

6. Małdyk H, Fiedorowicz-Fabrycy I. Układowe zapalenie naczyń. Reumatologia 2004; 42 (supl. 1): 86-87.

7. Romicka A, Rostropowicz-Denisiewicz K. Plamica Schonleina-Henocha. Zarys reumatologii wieku rozwojowego. Wydawnictwo Elamed, Katowice 2010; 133-135.

8. Zapalenie naczyń związane z IgA. Interna Szczeklika. Medycyna Praktyczna, Kraków 2014; 1889-1890.

9. Jaliman D. Henoch-Schonlein Purpura. July 12, 2013. 2013 WebMD.

10. Maj J, Reich A, Baran E. Pierwotne systemowe zapalenie naczyń. PSV. Postępy Dermatologii i Alergologii 2004; 21: 247254.

11. Jennette JC, Falk RJ, Bacon PA, et al. 2012 Revised International Chapel Hill Consensus Conference Nomenclature of Vasculitides. Arthritis Rheum 2013; 65: 1-11.

12. Brogan P, Elefherion D, Dillon M. Small vessel vasculitis. Pediatr Nephrol 2010; 25: 1025-1035.

13. Zaffarello M, Fanos V. Treatment-based literature of Henoch-Schonlein purpura nephritis in childhood. Pediatr Nephrol 2009; 24: 1901-1911. 
14. Frigui M, Lehiani D, Konbae M. Acute pancreatic as initial manifestation of adult Henoch-Schonlein purpura: raport of case and review of literature. Eur J Gastroenteral Hepatol 2011; 23: 189-192.

15. Zimmermann-Górska I. Plamica Henocha-Schönleina. Reumatologia kliniczna. Wydawnictwo Lekarskie PZWL, Warszawa 2008; 1019-1020.

16. Rieu P, Noel H. Henoch-Schonlein nephritis in children and adults, morphological features and clinicopathological correlations. Ann Med Interna 1999; 150: 151-159.

17. López Meiller MJ, Cavallasca JA, Maliandi Mdel R, Nasswetter GG. Henoch-Schonlein purpura in adults. Clinics 2008; 63: 273-276.

18. Wiland P, Madej M. Zapalenie naczyń. Przegląd Reumatologiczny 2007; 3-5. 